International Journal of Social Science and Economic Research

ISSN: 2455-8834

Volume:06, Issue:07 "July 2021"

\title{
THE EFFECT AND INFLUENCE OF THE DECOY PRICE ON CONSUMER PREFERENCES
}

\author{
Hadeel Manimaran \\ APL Global School \\ DOI: 10.46609/IJSSER.2021.v06i07.020 URL: https://doi.org/10.46609/IJSSER.2021.v06i07.020
}

\begin{abstract}
A choice is defined as a range of possibilities from which one may be chosen. Deeply exploring why people make the choices they do, a conclusion arises based on Rational choice theory:Individuals make choices maximizing their interests and ones that provide them with the greatest benefit. If this theory is applied on the purchase of products, a choice should be based solely on the pros and cons of the two options. But if a third option is thrown in, is there a possibility of affecting economic thinking to the extent of shifting the consumer's preference from one of the original options to another. The decoy effect shines a light on the influence of a third option that's not been produced as a viable choice rather exclusively to shift the choice between the original options. The decoy effect has been a highly challenged and controversial topic in the past couple of decades due to the conditions in which it has been proved being very specific and multiple unsuccessful replications. In this article, we take a look at the phenomenon in general, the theory it's based on a few examples where it has been proved.
\end{abstract}

\section{INTRODUCTION}

We're at a movie theatre with a couple of our friends and want to buy nachos to eat during the film. There are two options: a large box and a small box whose prices are quite far apart. The large box is $\$ 20$ and the small box is $\$ 10$. We feel that the large box is too expensive, overpriced, and not worth buying for $\$ 20$. Sowe turn to the counter to buy the smaller option. When we tell the cashier our order, he points out a medium box of nachos worth $\$ 17$ that we had completely missed. Now we change our mind and want to buy the medium-sized box as we think there aren't enough nachos in the small one. But on the other hand, the large box and the medium-sized box aren't very far apart in price. So, we think it would be economical for us to buy the large box instead, as it's a lot more nachos for just a couple of dollars more. We end up buying the large box and leave to watch the movie. In this case, we changed our choice from the small box to the large box in the presence of the medium box, although when the medium box wasn't present, we were about to buy the small box. 
The presence of an alternative option which logically speaking, had nothing to do with the original ones made us choose arguably the lesser economical option.

\section{THEORY}

\section{A) FAMOUS EXAMPLE OF DECOY EFFECT}

Dan Ariely, a professor at MIT noticed an interesting phenomenon on The Economist subscription page.

His students were split in two groups

Group 1 were offered two options:

A web only subscription or a Print + Web subscription.

Web only was picked by $68 \%$ and $32 \%$ chose both print and web

Group 2 on the other hand were presented three options:

\section{Web only, Print only or Print + Web}

$16 \%$ chose web only, none chose print only and $84 \%$ chose both.

The introduction of a third option changed the no. of people who chose the target by 52\%.[3] 
International Journal of Social Science and Economic Research

ISSN: 2455-8834

Volume:06, Issue:07 "July 2021"

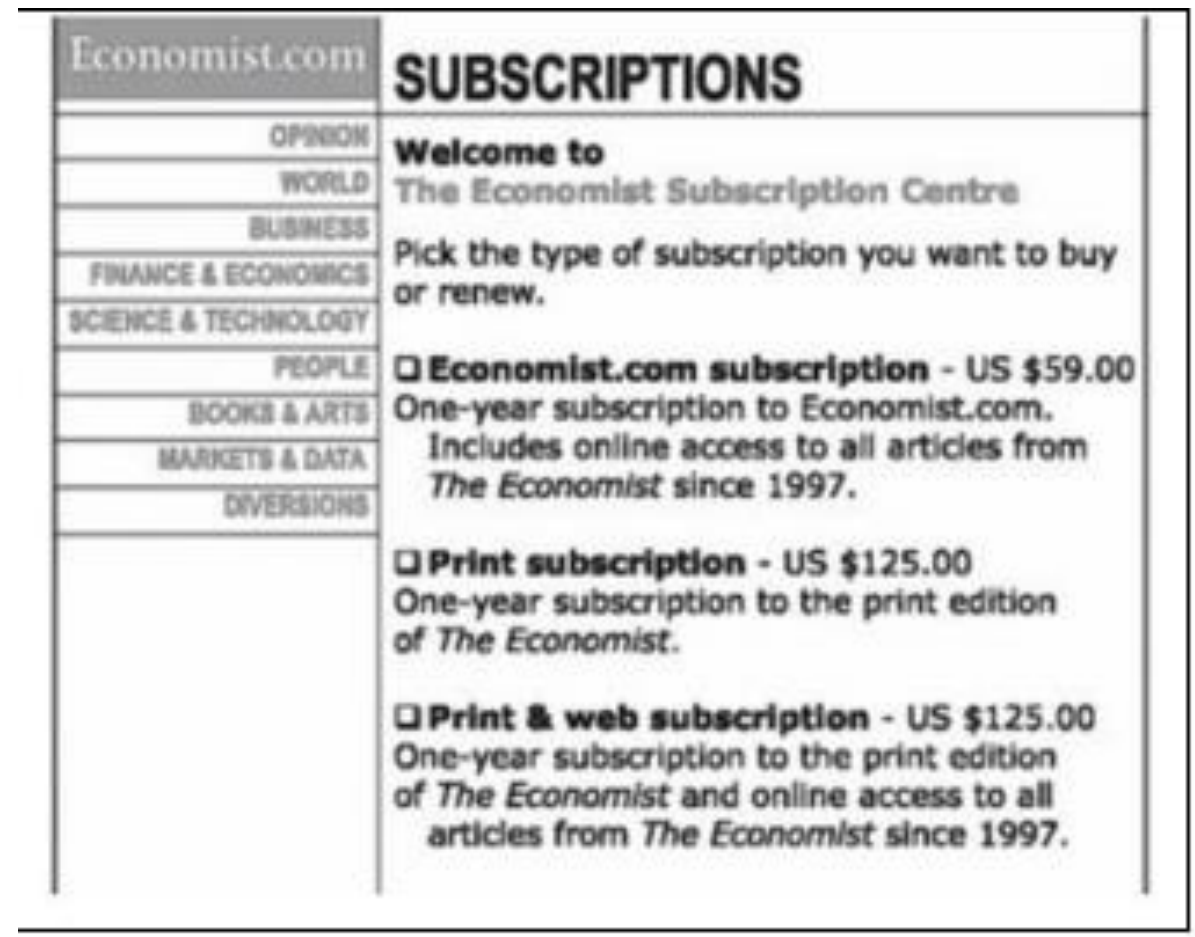

Fig 1- Economist subscription

\section{B) THE WORKING OF THE DECOY}

The decoy effect (also known as asymmetric dominance effect) is an anomaly in the concept of rational economic theory. Instead it perpetuates another based on irrational psychological bias. According to literature, people may be inclined to shift from one option to another by the presence of a third alternative ( the decoy) which rationally should not be influencing the choice in any way, shape or form.

To understand the concept, the choices need to be clear:-

1) Target :- This is the choice companies want you to make. It's the product that provides them the most monetary gain and the product that provides you the least economic value.

2) Competitor:- This is the option that is the alternative choice to the target. It's also the product they don't want you to choose although you might probably favor it at the start.

3) Decoy:- This is the third alternative which they hope will switch your choice from the competitor to the target when it is added to the mix.[3] 
International Journal of Social Science and Economic Research

ISSN: 2455-8834

Volume:06, Issue:07 "July 2021"

Decoys make you change the value you assign to the target. It switches the attributes you choose to focus on and find desirable. You move from comparing the products as a whole against one another to comparing a specific attribute of the target against the decoyand makes the target look like a safer option compared to the decoy. The introduction of a decoy switches the context of the choice completely.

\section{C) CHALLENGES OF THE DECOY EFFECT}

The reason why the decoy effect is an extremely debatable issue is because of the highly specific conditions required for it to work.

The positioning of the decoy is one such condition:- The reversal of choice is solely hinged on the positioning of the decoy and it's comparison to the target. If the decoy is too close to the target, there wouldn't be much difference between the target and the decoy, and wouldn't induce choice reversal. Alternatively, if the decoy is too far away from the target, consumers might not regard it to be a viable alternative.

There in lies the crux of the problem, the level of success of a decoy is dependant on the consumer.

1) The producer/company must be able to position a decoy in a way that's capable of standardizing the decoy-dominant relationships over the competition. Products generally have various attributes and alternatives. Consumers tend to look at all the attributes before making a choice on the product and the level of desire of a certain attribute can vary from costumer to costumer-What might be a decoy to one might not be a decoy to another.A decoy needs to catch the balance of multiple attributes, but the most widely used decoy (asymmetric decoys) completely dominates one particular attribute while the other attributes might be superior in the competitor.

2) The consumer should be able to detect the decoy-dominant relationship. As a certain product has multiple attributes-price, weight, quality etc. This makes it harder for customers to compare and contrast the target $\mathrm{v}$ decoy.

3) In some cases, the choice might be too trivial for the decoy to matter. In other circumstances, such as repeated products, the decoy doesn't affect the choice as customers might have experience with the competition.

4) Positioning of the decoy is also prevelant in pricing. Decoy-dominant relationships which consist of slightly inferior quality and a higher price might generate bad press for the company which in turn might drive customers way from the company. 
International Journal of Social Science and Economic Research

ISSN: 2455-8834

Volume:06, Issue:07 "July 2021"

Therefore, a situation that applies the decoy effect will only succeed in a product based in the following conditions:-

a) A significantly limited number of attributes

b) Not repeatedly purchased

c) Accurate pricing

\section{D) THE DIAMOND DECOY EFFECT-WU AND COSGUNER}

$\mathrm{Wu}$ and Cosguner use the diamond market as a suitable study. The quality of diamonds are based on 4 attributes: carat, colour, cut and clarity. The purchase isn't repeated and pricing is easy to observe. By segregating each diamond into one of four categories: Decoy only, Dominant only, Both and Neither, they managed to show not only that decoy only diamonds has the least sales while dominant only had the most but the presence of the decoy only option increased the sales of the dominant only. Another phenomenon observed was that the rates of identification of decoy-dominant detection varied according to price. Consumers were more likely to detect these relationships at below 2000\$ than at higher prices. Wu and Cosguner relate this to consumers on tight budgets looking for better deals.

Table 2: Summary Statistics Across Diamond Types

\begin{tabular}{lcc}
\hline Diamond Type & Diamond-Day Observations & Daily Percentage Sales \\
\hline Neither decoy nor dominant & 27,077 & $1.96 \%$ \\
Decoy only & 404,283 & $1.68 \%$ \\
Dominant only & 340,456 & $2.53 \%$ \\
Both decoy and dominant & $1,945,009$ & $2.08 \%$ \\
Total & $2,716,825$ & $2.07 \%$ \\
\hline
\end{tabular}

\section{Fig.2- Dominant and Decoys}

The detection in general was very low at about $11 \%$ but when it was detected sales raised by 1.8 to 3.2 times. They also quantified the monetary impact of the DE system, which increased the gross profit by $14.3 \%$. They proved the DE with market-level decoy dominant detection and the sales increasing upon the detection. 
International Journal of Social Science and Economic Research

ISSN: 2455-8834

Volume:06, Issue:07 "July 2021"

Table 8: The Impact of the DE on Retailer's Gross Profit

\begin{tabular}{lcccc}
\hline Effect & 2K-5K & $\mathbf{5 K}-\mathbf{1 0 K}$ & $\mathbf{1 0 K}-\mathbf{2 0 K}$ & Overall \\
\hline Avg Daily Profit Per Diamond W/O the DE & 8.71 & 30.17 & 43.67 & 22.89 \\
Avg Daily Profit Per Diamond W/ the DE & 10.92 & 32.76 & 49.72 & 26.16 \\
\% Profit Increase due to the DE & $25.37 \%$ & $8.58 \%$ & $13.85 \%$ & $14.29 \%$ \\
\hline
\end{tabular}

Fig.3- Gross Profit

\section{E) DECOY EFFECT IN DIGITAL MARKETING-SHERLIN AND SISWADH}

Sherlin and Siswadhi looked at the DE in Shopee, Indonesia. They tie the consumer's choice for a low involvement product with reviews. The decoy has limited reviews as it's meant to increase sales for the target and not itself. They sent a survey to 220 random participants presented with Shopee search results with a target item, competitor item and a decoy in different conditions. Their target product is a car trash bin. They set the competitor with a cheaper price, target with higher price and the decoy with a cheaper price than the target but a higher price than competitor.

\section{A. Theoretical Framework}

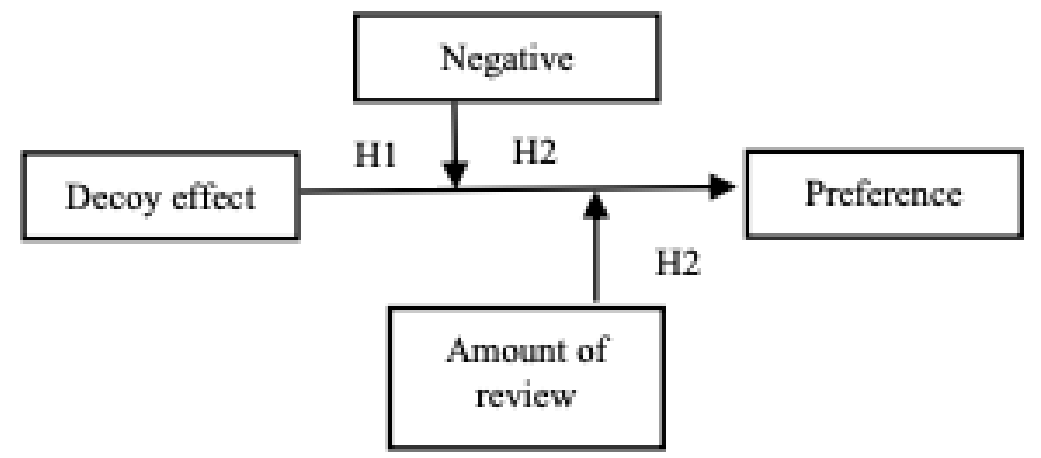

Fig.4- Reviews in the DE

Target item has a higher rating than the competitor.

They prove that DE exist in digital marketplace Shopee. Choices of online buyers can change towards lower involvement products by introducing a decoy that has negative reviews but is similar to the competitor. 
International Journal of Social Science and Economic Research

ISSN: 2455-8834

Volume:06, Issue:07 "July 2021"

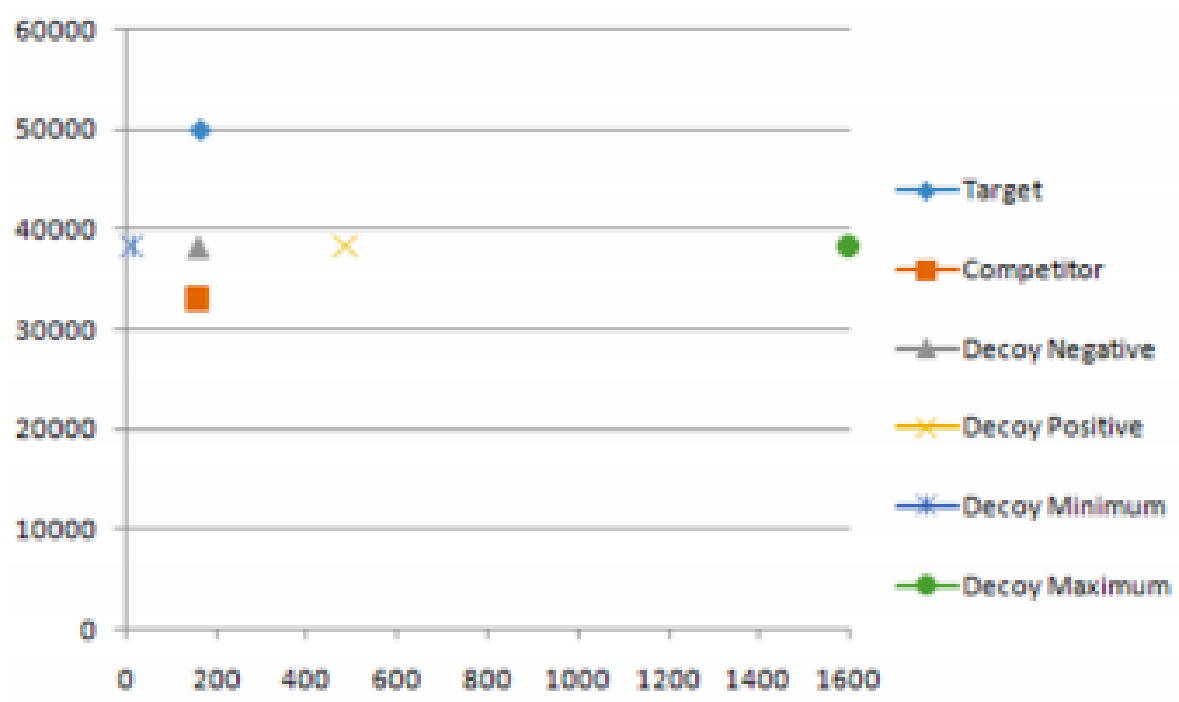

Fig.5- Sales Graph

\section{CONCLUSION}

From these studies it is clear that decoy-dominant relationships can work but need very specific conditions to do so. The positioning of the decoy is the most important part of the relationship and the unsuccessful studies is due to the failure to do so.

\section{References}

[1] Wu, Chunhua\&Cosguner, Koray. (2020). Profiting from the Decoy Effect: A Case Study of an Online Diamond Retailer. Marketing Science. 39. 974-995. 10.2139/ssrn.3271331.

[2] Kaptein, Maurits\& Emden, Robin \&Iannuzzi, Davide. (2016). Tracking the decoy: Maximizing the decoy effect through sequential experimentation. Palgrave Communications. 2. 16082. 10.1057/palcomms.2016.82.

[3] Sherlin, Intan\&Siswadhi, Ferry \&Sarmigi, Elex. (2020). Analysing the Decoy Effect on Online Product Purchasing Preference: An Experimental Study. 10.2991/aebmr.k.200331.027.

[4] Dornbusch and Fischer(2010). Macroeconomics $9^{\text {th }}$ edition.TataMcgraw Hill,Ch.6.4

[5] Pindych\&Others,microeconomics, A7 $7^{\text {th }}$ ed.Pearson,Ch.17 